Article

\title{
High-Accuracy Relative Biological Effectiveness Values Following Low-Dose Thermal Neutron Exposures Support Bimodal Quality Factor Response with Neutron Energy
}

\author{
Laura C. Paterson ${ }^{1,2}$, Amy Festarini ${ }^{1}$, Marilyne Stuart ${ }^{1}$, Fawaz Ali ${ }^{1}$, Christie Costello ${ }^{1}$, Chad Boyer ${ }^{1}$, \\ Ronald Rogge ${ }^{1}$, Norma Ybarra ${ }^{2,3}$, John Kildea ${ }^{3}(\mathbb{D})$ and Richard B. Richardson ${ }^{1,3, *}$ \\ 1 Canadian Nuclear Laboratories (CNL), Chalk River, ON K0J 1J0, Canada; laura.paterson@cnl.ca (L.C.P.); \\ amy.festarini@cnl.ca (A.F.); marilyne.stuart@cnl.ca (M.S.); fawaz.ali@cnl.ca (F.A.); \\ christie.costello@cnl.ca (C.C.); chad.boyer@cnl.ca (C.B.); ron.rogge@cnl.ca (R.R.) \\ 2 Division of Experimental Medicine, McGill University, Montreal, QC H4A 3J1, Canada; \\ norma.ybarra@mcgill.ca \\ 3 Medical Physics Unit, Montreal, QC H4A 3J1, Canada; john.kildea@mcgill.ca \\ * Correspondence: richard.richardson@cnl.ca
}

check for updates

Citation: Paterson, L.C.; Festarini, A.; Stuart, M.; Ali, F.; Costello, C.; Boyer, C.; Rogge, R.; Ybarra, N.; Kildea, J.; Richardson, R.B. High-Accuracy Relative Biological Effectiveness Values Following Low-Dose Thermal Neutron Exposures Support Bimodal Quality Factor Response with Neutron Energy. Int. J. Mol. Sci. 2022, 23, 878. https://doi.org/10.3390/ ijms23020878

Academic Editors: Andreyan N. Osipov and Dmitry Klokov

Received: 30 November 2021 Accepted: 30 December 2021 Published: 14 January 2022

Publisher's Note: MDPI stays neutral with regard to jurisdictional claims in published maps and institutional affiliations.

Copyright: (C) 2022 by the authors. Licensee MDPI, Basel, Switzerland. This article is an open access article distributed under the terms and conditions of the Creative Commons Attribution (CC BY) license (https:// creativecommons.org/licenses/by/ $4.0 /)$.

\begin{abstract}
Theoretical evaluations indicate the radiation weighting factor for thermal neutrons differs from the current International Commission on Radiological Protection (ICRP) recommended value of 2.5 , which has radiation protection implications for high-energy radiotherapy, inside spacecraft, on the lunar or Martian surface, and in nuclear reactor workplaces. We examined the relative biological effectiveness (RBE) of DNA damage generated by thermal neutrons compared to gamma radiation Whole blood was irradiated by $64 \mathrm{meV}$ thermal neutrons from the National Research Universal reactor. DNA damage and erroneous DNA double-strand break repair was evaluated by dicentric chromosome assay (DCA) and cytokinesis-block micronucleus (CBMN) assay with low doses ranging 6-85 mGy. Linear dose responses were observed. Significant DNA aberration clustering was found indicative of high ionizing density radiation. When the dose contribution of both the ${ }^{14} \mathrm{~N}(n, p){ }^{14} \mathrm{C}$ and ${ }^{1} \mathrm{H}(\mathrm{n}, \gamma)^{2} \mathrm{H}$ capture reactions were considered, the DCA and the CBMN assays generated similar maximum RBE values of $11.3 \pm 1.6$ and $9.0 \pm 1.1$, respectively. Consequently, thermal neutron RBE is approximately four times higher than the current ICRP radiation weighting factor value of 2.5. This lends support to bimodal peaks in the quality factor for RBE neutron energy response, underlining the importance of radiological protection against thermal neutron exposures.
\end{abstract}

Keywords: RBE; thermal neutron; dicentric chromosome; DCA; micronucleus; CBMN; biological dosimetry

\section{Introduction}

Secondary neutrons generated during proton and high-energy photon radiotherapy have been highlighted as a source of additional patient dose [1] and a risk factor for second malignant neoplasms [2,3]. Low-energy thermal neutrons comprise a notable fraction of these radiotherapy neutron fields [1]. Thermal neutrons have also been measured in CANada Deuterium Uranium (CANDU) reactor workplaces [4], in space [5,6], in highaltitude aircraft [7], and on the lunar surface [8]. Approximately 50\% of thermal neutrons penetrate up to $2 \mathrm{~cm}$ into a tissue phantom, with a maximum range of over $10 \mathrm{~cm}$ [9]. The current recommendations from the International Commission on Radiological Protection (ICRP) indicate a radiation weighting factor $\left(w_{R}\right)$ for thermal neutrons of 2.5 , in contrast to a weighting factor of unity for the sparse ionization of low linear energy transfer (LET) radiation such as photons and electrons [10]. Neutron $w_{\mathrm{R}}$ is a continuous function with energy, increasing from 2.5 at thermal and epithermal energies, up to a maximum of 20 at $1 \mathrm{MeV}$. Other high-LET particles, such as alpha particles, fission fragments, and heavy 
nuclei have also been ascribed a $w_{\mathrm{R}}$ of 20 [10]. Monte Carlo simulations have indicated that the quality factor for thermal neutrons may be closer to 20 [11,12], and previous first-principles calculations and microdosimetric evaluations have demonstrated that the energy-dependent neutron quality factor follows a bimodal distribution with a peak near the thermal-neutron energy range and another in the fast-neutron energy range $[13,14]$ (Figure 1). To investigate the discrepancy between the ICRP radiation weighting factor, $w_{\mathrm{R}}$ and the reported quality factors, we experimentally evaluated the relative biological effectiveness (RBE) of low-dose, low-energy thermal neutrons in human peripheral blood lymphocytes. The RBE is a dimensionless quantity that describes the ability of a particular radiation type to produce a certain biological effect when compared to a reference radiation that is typically low-LET gamma rays or X-rays. RBE from animal studies, cell-killing, and chromosome aberration analysis influence the theoretically derived ICRP $w_{\mathrm{R}}$ values; however, unlike $\mathrm{RBE}, w_{\mathrm{R}}$ accounts for the varying biological effects induced by different radiation types and take into account all possible biological consequences of a particular radiation [10]. In contrast, $\mathrm{RBE}$ values vary with multiple parameters including dose, dose rate, biological endpoint, cell type, cell-cycle phase, sample volume, sample depth, and microenvironment [15]. As a result, RBE and $w_{R}$ values are similar but not necessarily equal.

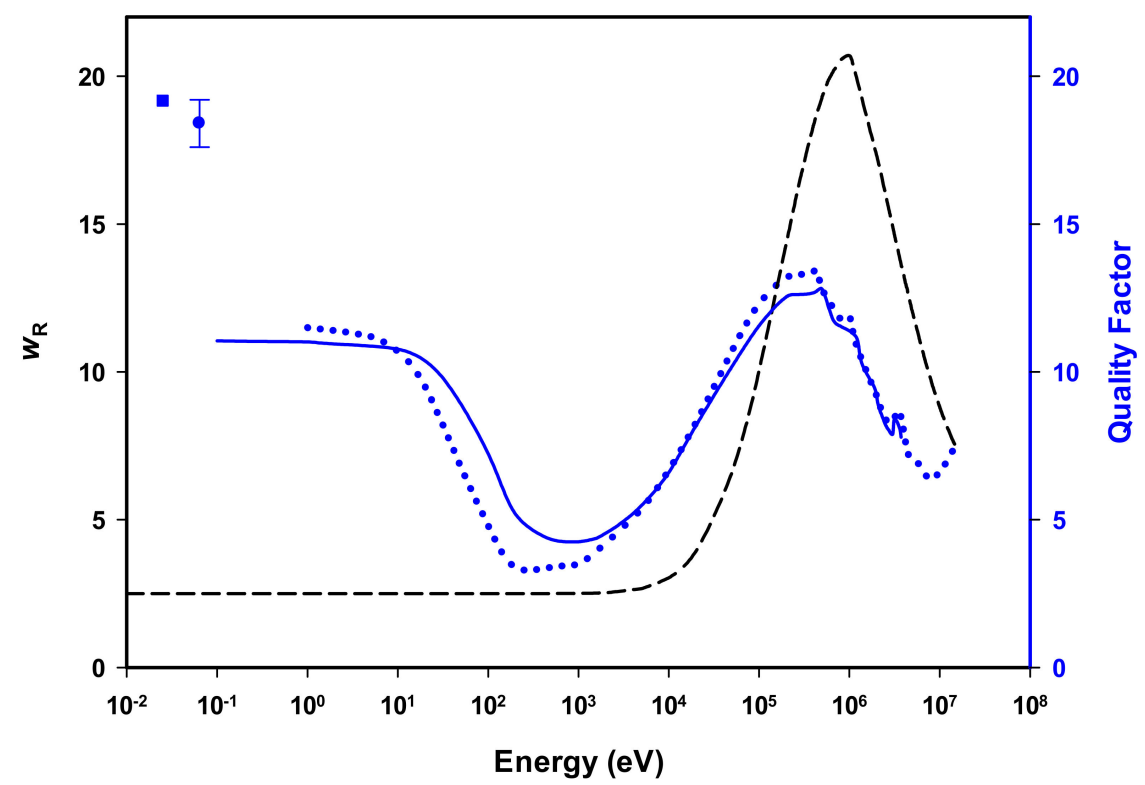

Figure 1. Illustration showing comparison of ICRP neutron radiation weighting factor $w_{\mathrm{R}}$ (black dashed line) [10], and smoothed quality factor distributions calculated by Cross and Ing (blue dotted line) [13] and by Stinchcomb and Borak (blue solid line) [14], and thermal neutron quality factors calculated by Schuhmacher and Seibert (blue square) [11] and Ali et al. (blue circle) [12].

Evaluations of the dicentric chromosome assay (DCA) $\mathrm{RBE}_{\mathrm{M}}$ of low-energy thermal neutrons in human peripheral blood lymphocytes are reported in several previous publications (Table 1), with maximum $\mathrm{RBE}\left(\mathrm{RBE}_{\mathrm{M}}\right)$ results ranging from $10.8 \pm 1.8$ to $51.1 \pm 31.3$ [16-19]. The wide range of DCA RBE values and the large associated errors makes pinpointing a single thermal neutron RBE value difficult. There are currently no studies describing thermal neutron RBE using alternative endpoints. The International Atomic Energy Agency recommends cytogenetic assays used for dose assessment for photon equivalent dose range 0.1-5 Gy for the DCA and 0.3-4 Gy for the cytokinesis-block micronucleus assay (CBMN) assay [20]. However, the high ionization density and greater DNA damage potential of the thermal neutron exposures justify use of these assays at lower absorbed doses. 
Table 1. Comparison of DCA RBE $\mathrm{M}$ and linear regression ( $\alpha$ coefficient) values in human peripheral blood lymphocytes following thermal neutron exposure.

\begin{tabular}{|c|c|c|c|c|c|c|}
\hline \multirow[b]{2}{*}{$\begin{array}{c}\text { Neutron Energy } \\
(\mathrm{meV})\end{array}$} & \multirow[b]{2}{*}{ Reference } & \multirow[b]{2}{*}{$\begin{array}{l}\text { Absorbed Dose } \\
\text { Ranges (Gy) }\end{array}$} & \multirow[b]{2}{*}{$\begin{array}{l}\text { \# Dose } \\
\text { Points }\end{array}$} & \multicolumn{2}{|c|}{ Regression } & \multirow[b]{2}{*}{$\mathrm{RBE}_{\mathbf{M}}$} \\
\hline & & & & $\begin{array}{c}\text { Neutron } \\
\alpha \pm \text { SE (Gy-1) }\end{array}$ & $\underset{\alpha \pm \text { SE (Gy-1) }}{\text { Gamma }}$ & \\
\hline 64 & This study & $0.006-0.082$ & 7 & $0.789 \pm 0.045$ & $0.070 \pm 0.0088^{a}$ & $11.3 \pm 1.6$ \\
\hline Thermal & Sevan'kaev et al. [16] & $0.16-0.64$ & 3 & $0.745 \pm 0.03^{b}$ & $0.069 \pm 0.011^{c}$ & $10.8 \pm 1.8^{b}$ \\
\hline Thermal & Wojcik et al. [17] & & 6 & $0.669 \pm 0.002$ & $0.055 \pm 0.023$ & 12.16 \\
\hline 25.3 & Schmid et al. [18] & $0.375-1.875$ & 5 & $0.400 \pm 0.018$ & $0.011 \pm 0.004^{\mathrm{d}}$ & $36.4 \pm 13.3$ \\
\hline 25 & Sasaki et al. [19] & $0.073-2.19$ & 7 & $0.920 \pm 0.028$ & $0.018 \pm 0.011^{\mathrm{e}}$ & $51.1 \pm 31.3$ \\
\hline
\end{tabular}

The number of dose points does not include unirradiated control samples. ${ }^{a}$ Flegal et al. [21]; ${ }^{b}$ Recalculated by Schmid et al. [18]; ${ }^{\mathrm{c}}$ Recalculated by Lloyd \& Edwards [22]; ${ }^{\mathrm{d}}$ Bauchinger et al. [23]; ${ }^{\mathrm{e}}$ Sasaki et al. [24].

Neutron irradiation can cause elevated levels of complex DNA lesions, notably doublestrand break (DSB) clusters and non-DSB clusters, compared to X-ray radiation [25].

Experimental evaluations have demonstrated that high ionization density exposure results in clustering of DNA double strand breaks but similar DNA repair kinetics as compared to gamma [26]. Previous thermal neutron DCA studies cover evaluations of the presence of aberration clustering, leading to the predicted non-Poisson over-dispersion of dicentric and ring chromosomes at doses above $300 \mathrm{mGy}[18,19]$. Complex DNA DSB lesions, such as those generated by neutron exposure, are more difficult to repair than the lesions generated by low-LET radiation, and may lead to genomic instability or carcinogenesis.

To facilitate thermal neutron RBE research, modifications were made to a neutronscattering beam line at the National Research Universal (NRU) reactor of the Canadian Nuclear Laboratories (CNL) to allow for biological sample exposures [12]. Two assays were used to quantify the effects of low-dose thermal neutrons: the DCA and the CBMN assay. The DCA is currently the gold-standard method used to assess absorbed dose following accidental radiation overexposures or large-scale radiological events [20]. This method evaluates DNA DSB mis-repair in $\mathrm{G}_{0}$ lymphocytes. In previous studies, a correlation has been demonstrated between the yield of radiation-induced dicentric and ring chromosomes and absorbed dose for in vivo and in vitro exposures for low- and high-LET radiations [20]. This assay can also be used to evaluate DNA DSB aberration clustering by testing for compliance with the Poisson distribution. The CBMN assay, which also evaluates DNA DSB-related events in $\mathrm{G}_{0}$ lymphocytes, has been proposed as a higher-throughput alternative to the DCA, as micronuclei induction likewise scales well with radiation dose. However, unlike the DCA, the background rate of micronucleus $(\mathrm{MN})$ generation varies significantly among individuals. Factors such as age, gender, diet, and smoking status have been found to impact endogenous MN frequency $[27,28]$. This work follows from a previous experimental low-dose neutron RBE investigation at CNL using ${ }^{252} \mathrm{Cf}$ fast neutrons [29].

The original aim of this study was twofold: to investigate DNA aberration clustering in the low-dose range, and to experimentally evaluate high-accuracy RBE for thermal neutrons. In view of the unexpectedly high RBE value acquired, a secondary aim was to provide some validity to the findings, as the high RBE value is commensurate with theoretical quality factor analyses for thermal neutrons carried out by microdosimetry and first-principles calculations.

\section{Results}

\subsection{Dicentric Chromosome Assay}

The DCA aberration distribution for three donors following $64 \mathrm{meV}$ thermal neutron exposure is presented in Table 2. A total of 13,819 cells from three donors were scored across eight dose points, up to a total dose of $82.1 \mathrm{mGy}$, yielding 273 dicentric and ring chromosome aberrations. The background yield was 0.0004 aberrations per cell, and the maximum aberration yield was 0.0627 aberrations per cell. The majority of cells had no aberrations. At the highest dose point of $82.1 \mathrm{mGy}$, only approximately $6 \%$ of cells 
contained between one and three dicentric and/or centric ring aberrations. Five of the seven irradiated data points demonstrated non-Poisson over-dispersion with values of $u>1.96$ (Table 2). Only the $12.0 \mathrm{mGy}$ and $23.9 \mathrm{mGy}$ dose points did not achieve the predicted over-dispersion.

Table 2. DCA aberration distribution in the peripheral blood lymphocytes of three donors and dose-specific RBE values following $64 \mathrm{meV}$ thermal neutron exposure. Values of $u$ demonstrating non-Poisson over-dispersion are highlighted in bold. The dose is reported as the mean dose with standard error (SE).

\begin{tabular}{|c|c|c|c|c|c|c|c|c|c|c|c|c|c|c|c|}
\hline \multirow{2}{*}{$\begin{array}{c}\text { Total Dose } \\
\pm \text { SE } \\
(\mathrm{mGy})\end{array}$} & \multirow{2}{*}{$\begin{array}{l}(\mathrm{n}, \mathrm{p}) \\
\text { Dose } \\
(\mathrm{mG})\end{array}$} & \multirow{2}{*}{$\begin{array}{l}(\mathrm{n}, \gamma) \\
\text { Dose } \\
(\mathrm{mG})\end{array}$} & \multirow{2}{*}{$\begin{array}{l}\text { Cells } \\
\text { Scored }\end{array}$} & \multirow{2}{*}{$\begin{array}{c}\text { Total } \\
\text { Aberr. } \\
( \pm S D) *\end{array}$} & \multicolumn{4}{|c|}{$\begin{array}{c}\text { Distribution of } \\
\text { Aberr. }\end{array}$} & \multirow{2}{*}{$\begin{array}{c}\text { Total } \\
\text { Aberr. } \\
\text { per Cell }\end{array}$} & \multirow{2}{*}{$\begin{array}{c}\text { (n,p) } \\
\text { Aberr. } \\
\text { per Cell }\end{array}$} & \multirow{2}{*}{$\begin{array}{c}(\mathrm{n}, \gamma) \\
\text { Aberr. } \\
\text { per Cell }\end{array}$} & \multirow{2}{*}{$\sigma^{2} / y$} & \multirow[t]{2}{*}{$u$} & \multirow{2}{*}{$\begin{array}{c}(\mathbf{n}, \mathbf{p})+ \\
(\mathbf{n}, \gamma) \\
\text { RBE }\end{array}$} & \multirow{2}{*}{$\begin{array}{l}\text { (n,p) } \\
\text { RBE }\end{array}$} \\
\hline & & & & & 0 & 1 & 2 & 3 & & & & & & & \\
\hline $0 \pm 0$ & 0 & 0 & 2800 & $1 \pm 1$ & 2799 & 1 & 0 & 0 & 0.0004 & 0.0004 & 0 & 1.00 & -. &.- & - \\
\hline $6.0 \pm 0.2$ & 4.2 & 1.8 & 1500 & $7 \pm 3$ & 1494 & 5 & 1 & 0 & 0.0047 & 0.0046 & 0.0001 & 1.28 & 8.34 & 11 & 15 \\
\hline $12.0 \pm 0.3$ & 8.5 & 3.5 & 1414 & $11 \pm 3$ & 1404 & 11 & 0 & 0 & 0.0067 & 0.0065 & 0.0002 & 0.99 & -0.20 & 7 & 10 \\
\hline $21.0 \pm 0.4$ & 14.9 & 6.1 & 1500 & $26 \pm 5$ & 1478 & 18 & 4 & 0 & 0.0173 & 0.0169 & 0.0004 & 1.29 & 8.13 & 10 & 14 \\
\hline $23.9 \pm 0.6$ & 16.9 & 7.0 & 1500 & $32 \pm 6$ & 1469 & 30 & 1 & 0 & 0.0213 & 0.0208 & 0.0005 & 1.04 & 1.16 & 10 & 14 \\
\hline $42.2 \pm 0.6$ & 30.2 & 12.0 & 1500 & $50 \pm 7$ & 1456 & 39 & 4 & 1 & 0.0333 & 0.0325 & 0.0008 & 1.25 & 6.84 & 9 & 12 \\
\hline $61.9 \pm 0.7$ & 43.8 & 18.1 & 2030 & $101 \pm 10$ & 1940 & 80 & 9 & 1 & 0.0498 & 0.0485 & 0.0013 & 1.19 & 6.03 & 8 & 11 \\
\hline $82.1 \pm 1.8$ & 58.1 & 24.0 & 1575 & $102 \pm 10$ & 1487 & 75 & 12 & 1 & 0.0648 & 0.0631 & 0.0017 & 1.23 & 6.49 & 7 & 10 \\
\hline
\end{tabular}

Aberr., Aberrations. * Assuming Poisson distribution.

Figure 2 illustrates the linear $64 \mathrm{meV}$ thermal neutron dose response curves compared to the extrapolated ${ }^{137} \mathrm{Cs}$ reference radiation dose response curve [21]. Data points represent the mean of three independent experiments involving blood from three different donors. Error bars illustrate the standard error of the mean. Linear and linear-quadratic regressions were both evaluated, revealing a preference for a linear dose response due to the nonsignificant $z$-test result for the $\beta$ regression coefficient. The regression coefficients, the associated standard error values, results of the $\chi^{2}$ - and $z$-tests, and the $R^{2}$ values are presented in Table 3.

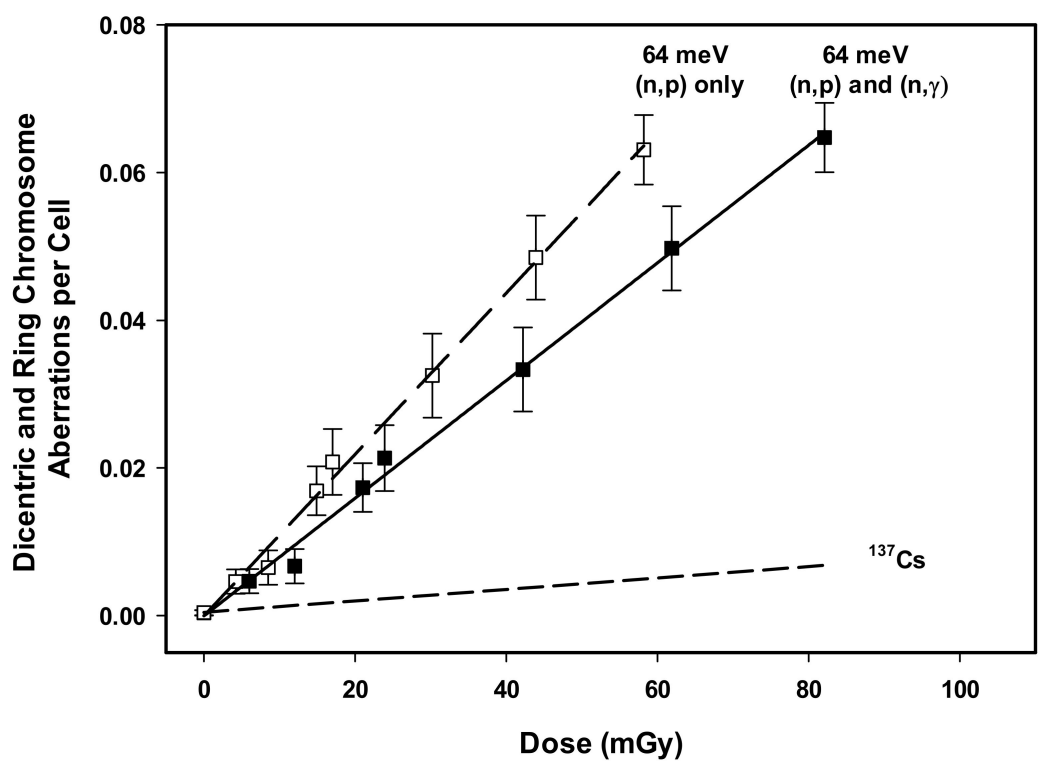

Figure 2. DCA linear dose response regression for the $64 \mathrm{meV}$ neutron exposures ((n,p) and (n, $\gamma)$, filled squares and solid line; only the (n,p) reaction, open squares and long-dash line), compared to the extrapolated ${ }^{137} \mathrm{Cs}$ curve (short-dash line) from the linear-quadratic dose response derived by Flegal et al. [21]. The graph details the relationship between radiation dose and the number of dicentric and centric ring chromosome aberrations per cell. Error bars represent standard error of the mean across three donors. 
Table 3. DCA linear dose response regression and $R^{2}$ values for $64 \mathrm{meV}$ thermal neutrons and ${ }^{137} \mathrm{Cs}$ photons.

\begin{tabular}{|c|c|c|c|c|c|c|c|}
\hline Radiation & Regression & {$[ \pm S E]^{\alpha}\left(G y^{-1}\right)$} & $\begin{array}{c}\beta \\
{[ \pm S E]\left(G^{-2}\right)}\end{array}$ & $\stackrel{c}{c}[ \pm \mathrm{SE}]$ & $\begin{array}{c}\chi_{\text {-Test }}^{2} \\
\text { Sig. }\end{array}$ & $\begin{array}{l}\alpha \text { z-Test } \\
\text { Sig. }\end{array}$ & $\begin{array}{c}\text { Pearson's } R^{2} \\
\text { Value }\end{array}$ \\
\hline $64 \mathrm{meV}(\mathrm{n}, \mathrm{p})+(\mathrm{n}, \gamma)$ & $A=0.0003+0.789 D$ & $0.789 \pm 0.045$ & - & $0.0003 \pm 0.0017$ & 0.9867 & 0.00001 & 0.998 \\
\hline $64 \mathrm{meV}(\mathrm{n}, \mathrm{p})$ only & $A=0.0003+1.088 D$ & $1.088 \pm 0.063$ & - & $0.0003 \pm 0.0021$ & 0.9948 & 0.00001 & 0.999 \\
\hline${ }^{137}$ Cs $[21]$ & $A=0.070 D+0.061 D^{2}$ & $0.070 \pm 0.0088$ & $0.061 \pm 0.0043$ & - & - & - & - \\
\hline
\end{tabular}

$A$, Aberrations per cell; $\alpha, \beta, c$, regression coefficients; $D$, Dose (Gy); $R^{2}$, coefficient of determination; Sig., Significance.

\subsection{Cytokinesis-Block Micronucleus Assay}

Employing the CBMN assay, a total of 75,000 bi-nucleated (BN) cells from three independent donors were examined across five dose points, yielding 3182 micronuclei. As a function of dose, the aberration yield following exposure to $64 \mathrm{meV}$ neutrons varied between 243 aberrations in 15,000 BN cells at $0 \mathrm{mGy}$ to 1036 aberrations in 15,000 BN cells at $85.0 \pm 1.6 \mathrm{mGy}$ (Table 4$)$. Therefore, the background yield was $0.016 \mathrm{MN}$ per cell, and the maximum aberration yield was $0.069 \mathrm{MN}$ per cell. The majority of cells had no $\mathrm{MN}$, even at the highest dose point where approximately $7 \%$ of cells revealed one to three MN. Highly damaged cells with three MN represent only $0.07 \%$ at the highest dose. The average proliferative index for the $0 \mathrm{mGy}$ control sample was found to be 1.7. Standard errors for dose and $\mathrm{MN}$ frequency represent the difference across the three blood donors. Figure 3 illustrates the linear $64 \mathrm{meV}$ thermal neutron CBMN dose response curve and the extrapolated ${ }^{60} \mathrm{Co}$ reference radiation dose response curve [30]. All five exposures demonstrated non-Poisson over-dispersion with values of $u>1.96$, including the $0 \mathrm{mGy}$ dose point, which is a characteristic of the CBMN assay (Table 4). Linear and linearquadratic regression were both evaluated. As with the DCA, there was a preference for linear regression due to the non-significant $z$-test result for the $\beta$ coefficient. The regression coefficients, the associated standard error values, results of the $\chi^{2}$ - and $z$-tests, and the $R^{2}$ values are presented in Table 5 .

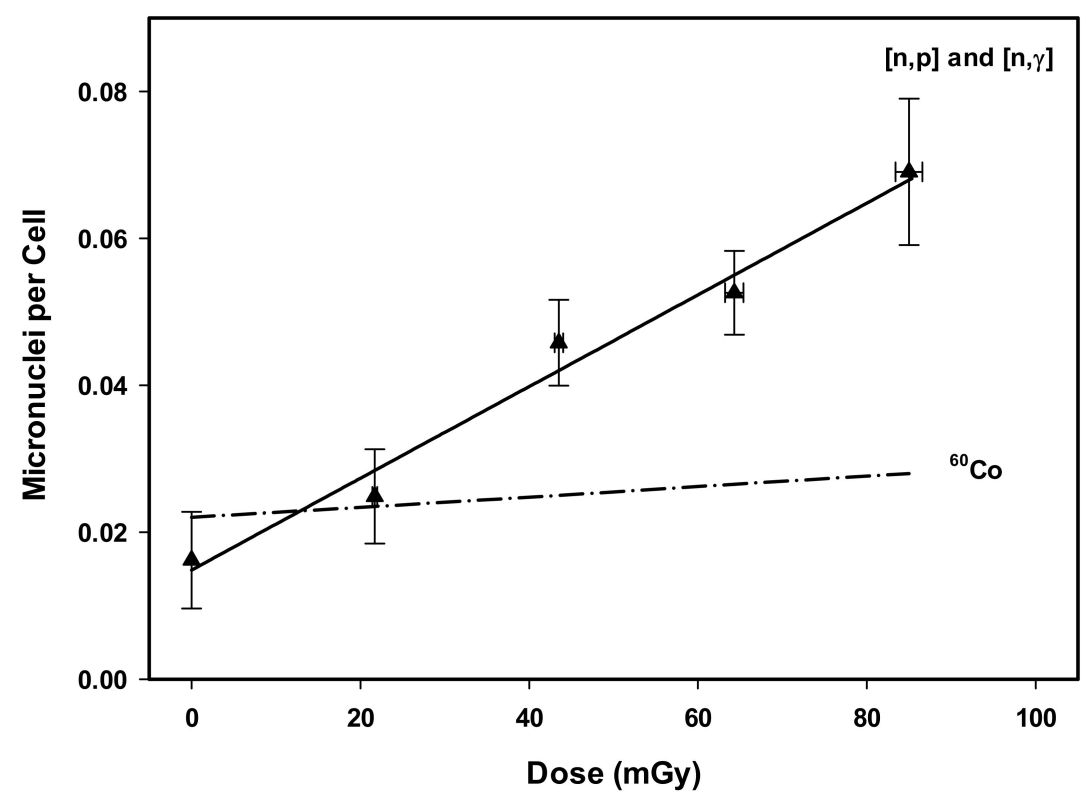

Figure 3. CBMN linear dose response regression (filled triangles, solid line) for $64 \mathrm{meV}$ thermal neutron exposures compared to the extrapolated ${ }^{60} \mathrm{Co}$ curve (dash-dot line) generated from the linear quadratic dose response derived by McNamee et al. [30], detailing the relationship between radiation dose and the number of micronuclei per cell. Error bars represent standard error of the mean across three donors. 
Table 4. CBMN distribution in the peripheral blood lymphocytes of three donors and dose-specific RBE values. Values of $u$ demonstrating non-Poisson over-dispersion are highlighted in bold. Standard error of the mean represents the error for the dose across three donors.

\begin{tabular}{|c|c|c|c|c|c|c|c|c|c|c|c|c|}
\hline \multirow{2}{*}{$\begin{array}{c}\text { Total Dose } \\
\pm \text { SE } \\
(\mathrm{mGy})\end{array}$} & \multirow{2}{*}{$\begin{array}{l}\text { (n,p) } \\
\text { Dose } \\
(\mathrm{mGy})\end{array}$} & \multirow{2}{*}{$\begin{array}{c}(\mathrm{n}, \gamma) \\
\text { Dose } \\
(\mathrm{mG})\end{array}$} & \multirow{2}{*}{$\begin{array}{l}\text { Cells } \\
\text { Scored }\end{array}$} & \multirow{2}{*}{$\begin{array}{l}\text { Total Aberr. } \\
\quad\left( \pm S D^{*}\right)\end{array}$} & \multicolumn{4}{|c|}{ Distribution of Aberr. } & \multirow{2}{*}{$\begin{array}{l}\text { Total Aberr. } \\
\text { per Cell }\end{array}$} & \multirow{2}{*}{$\sigma^{2} / y$} & \multirow{2}{*}{$u$} & \multirow{2}{*}{$\begin{array}{c}(\mathrm{n}, \mathrm{p})+ \\
(\mathrm{n}, \gamma) \\
\mathrm{RBE}\end{array}$} \\
\hline & & & & & 0 & 1 & 2 & 3 & & & & \\
\hline $0 \pm 0$ & 0 & 0 & 15000 & $243 \pm 16$ & 14757 & 216 & 12 & 1 & 0.0162 & 1.11 & 9.31 & - \\
\hline $21.7 \pm 0.3$ & 15.4 & 6.3 & 15000 & $373 \pm 19$ & 14627 & 281 & 37 & 6 & 0.0249 & 1.27 & 23.42 & 8 \\
\hline $43.5 \pm 0.5$ & 30.8 & 12.7 & 15000 & $687 \pm 26$ & 14313 & 499 & 82 & 8 & 0.0458 & 1.26 & 22.76 & 8 \\
\hline $64.3 \pm 1.1$ & 45.5 & 18.8 & 15000 & $789 \pm 28$ & 14211 & 578 & 83 & 15 & 0.0526 & 1.27 & 23.53 & 7 \\
\hline $85.0 \pm 1.6$ & 60.1 & 24.9 & 15000 & $1036 \pm 32$ & 13964 & 759 & 122 & 11 & 0.0691 & 1.23 & 19.89 & 7 \\
\hline
\end{tabular}

Aberr., Aberrations. * Assuming Poisson distribution.

Table 5. CBMN linear dose response regression for $64 \mathrm{meV}$ thermal neutrons and ${ }^{60} \mathrm{Co}$ photons.

\begin{tabular}{|c|c|c|c|c|c|c|c|}
\hline Radiation & Regression & $\begin{array}{c}A \\
{[ \pm \mathrm{SE}]\left(\mathrm{Gy}^{-1}\right)}\end{array}$ & $\begin{array}{c}\beta \\
{[ \pm \mathrm{SE}]\left(\mathrm{Gy}^{-2}\right)}\end{array}$ & $\begin{array}{c}c \\
{[ \pm \mathrm{SE}]}\end{array}$ & $\begin{array}{l}\chi_{\text {Sig. }}^{2} \text {-Test } \\
\text { ing }\end{array}$ & $\begin{array}{l}\alpha \text { z-Test } \\
\text { Sig. }\end{array}$ & $\begin{array}{c}\text { Pearson's } R^{2} \\
\text { Value }\end{array}$ \\
\hline $64 \mathrm{meV}(\mathrm{n}, \mathrm{p})$ & $A=0.0153+$ & $0.615 \pm 0.052$ & - & $0.0153 \pm 0.0085$ & 0.0013 & 0.0013 & 0.98 \\
\hline${ }^{60} \mathrm{Co}[30]$ & $A=0.022+0.068 D+0.024 D^{2}$ & $0.068 \pm 0.006$ & $0.024 \pm 0.0020$ & $0.022 \pm 0.0020$ & - & - & - \\
\hline
\end{tabular}

Abbreviations: A: Aberrations per cell, $\alpha, \beta, c$ : regression coefficients, $D$ : Dose (Gy), $R^{2}$ : coefficient of determination, Sig.: Significance.

\subsection{Relative Biological Effectiveness}

For the DCA in which the nitrogen, ${ }^{14} \mathrm{~N}(\mathrm{n}, \mathrm{p}){ }^{14} \mathrm{C}$ and hydrogen, ${ }^{1} \mathrm{H}(\mathrm{n}, \gamma)^{2} \mathrm{H}$ capture reactions were considered together, a DCA $\mathrm{RBE}_{\mathrm{M}}$ value of $11.3 \pm 1.6$ was found when referenced to ${ }^{137} \mathrm{Cs}$ exposures [21]. Similarly, when the results of only the ${ }^{14} \mathrm{~N}(n, p){ }^{14} \mathrm{C}$ reaction was evaluated, an elevated, but not significantly different, $\mathrm{RBE}_{\mathrm{M}}$ of $15.5 \pm 2.2$ was revealed $(z=1.54, p=0.123)$. As presented in Table 2 , dose-specific DCA RBE values decreased with increasing dose and varied from 11 at $6 \mathrm{mGy}$ to 7 at $82.1 \mathrm{mGy}$, when both the ${ }^{14} \mathrm{~N}(\mathrm{n}, \mathrm{p}){ }^{14} \mathrm{C}$ and ${ }^{1} \mathrm{H}(\mathrm{n}, \gamma)^{2} \mathrm{H}$ capture reactions were considered, and from 15 to 10 when the effect of only the ${ }^{14} \mathrm{~N}(\mathrm{n}, \mathrm{p}){ }^{14} \mathrm{C}$ capture reaction was evaluated.

The CBMN assay revealed an $\mathrm{RBE}_{\mathrm{M}}$ value of $9.0 \pm 1.1$ for both the ${ }^{14} \mathrm{~N}(\mathrm{n}, \mathrm{p})^{14} \mathrm{C}$ and ${ }^{1} \mathrm{H}(\mathrm{n}, \gamma){ }^{2} \mathrm{H}$ capture reactions when referenced to ${ }^{60} \mathrm{Co}$ radiation [30]. Dose-specific CBMN RBE values decreased with increasing dose, revealing an RBE of 8 at the lowest dose of $21.7 \mathrm{mGy}$ and an RBE of 7 at the highest dose of $85.0 \mathrm{mGy}$.

\section{Discussion}

\subsection{DNA Aberration Clustering}

The majority of DCA dose points exhibited non-Poisson over-dispersion (Table 2). This confirms the presence of DNA aberration clustering, and is consistent with results from the higher-dose thermal neutron DCA studies $[18,19]$. Therefore, thermal neutron exposures in lymphocytes exhibit the track structure characteristics and associated DNA damage of high-LET radiations, which does not match the current ICRP $w_{R}$ recommendation of 2.5 . In biological dosimetry, traditionally 50 or fewer DCA cells are scored for triage biological dosimetry, and 500 to 1000 DCA cells are scored for detailed dose estimates [20,31]. Although over-dispersion of chromosome aberrations is considered a hallmark of high-LET radiation exposure, the data in Table 2 demonstrate that over-dispersion may not be immediately evident in low-dose neutron samples. For example, for the dose points that achieved over-dispersion, the removal of up to four cells containing two or more dicentric or ring chromosome aberrations per dose point was enough to rescind the over-dispersion effect in a sample size of over 1400. The failure to observe the predicted high-LET over-dispersion is especially likely for triage biological dosimetry where lower numbers of cells are scored; however, as demonstrated by the current study, over-dispersion is also possible when a higher numbers of cells are evaluated.

All CBMN assay data points were found to exhibit non-Poisson over-dispersion (Table 4). This finding was expected, as the tendency for over-dispersion is well documented 
for the CBMN assay following both low-LET photon exposures [20] and high-LET fastneutron exposures [32]. This is theorized to be due to the large number of cells with zero aberrations, a positive concurrence between micronuclei, or an association between the radiation dose and the associated error [33].

\subsection{Bimodal Neutron RBE Values}

Using the $z$-test with Holm's method to evaluate multiple comparisons, there was insufficient evidence to conclude that our DCA RBE $\mathrm{B}_{\mathrm{M}}$ value of $11.3 \pm 1.6$ (for both ${ }^{1} \mathrm{H}(\mathrm{n}, \gamma)^{2} \mathrm{H}$ and ${ }^{14} \mathrm{~N}(\mathrm{n}, \mathrm{p}){ }^{14} \mathrm{C}$ reactions) was different from any of the previously published $\mathrm{RBE}_{\mathrm{M}}$ data for thermal neutrons, including the values of $10.8 \pm 1.8$ found using data from Sevan'kaev et al. [16] (calculated by Schmid et al. [18]), $36.4 \pm 13.3$ reported by Schmid et al. [18], and $51.1 \pm 31.3$ described by Sasaki et al. [19]. This seemingly surprising result is partially due to the high variance of the latter two studies. For Schmid et al. [18] and Sasaki et al. [19], which revealed the largest RBE values of $36.4 \pm 13.3$ and $51.1 \pm 31.3$, respectively, the very low $\alpha$ regression coefficient of the gamma reference radiation (Table 1) played a significant role in the elevated RBE values.

Our data suggest that the linear dose response function is preferred for all endpoints. This finding is consistent with those of previous thermal neutron DCA studies [16-18]. As shown in Table 1, many of the previous thermal neutron DCA studies reported large RBE standard error values, or reported no error estimate at all.

There was no significant difference between our DCA $\mathrm{RBE}_{\mathrm{M}}$ of $11.3 \pm 1.6$ and the CBMN RBE $\mathrm{M}$ of $9.0 \pm 1.1(z=1.13, p=0.250)$, for both ${ }^{1} \mathrm{H}(\mathrm{n}, \gamma)^{2} \mathrm{H}$ and ${ }^{14} \mathrm{~N}(\mathrm{n}, \mathrm{p}){ }^{14} \mathrm{C}$ reactions. As both assays examine chromosome aberrations initiated by DNA DSBs, it is not surprising that the $\mathrm{RBE}_{\mathrm{M}}$ is similar.

During the irradiation period, a very low-dose gamma field was generated at the site of the thermal neutron exposures as consequence of gamma radiation escaping into the reactor beamline. This gamma field was not quantified, but control sample evaluations demonstrated that the total dose delivered to the samples was below the DCA threshold of gamma-ray detection of $0.1 \mathrm{~Gy}$ [21]. Previous studies have demonstrated that very low doses of gamma radiation in conjunction with, or in advance of, fast-neutron exposure can result in a protective effect whereby DNA damage is reduced in mixed-radiation exposures of peripheral blood lymphocytes [34,35]. It has been proposed that a hormetic effect caused by these low-dose gamma fields may be responsible for the large variation of RBE values found in the literature [35]. Although there is notable DCA RBE variation across thermal neutron studies (Table 1), external photon fields generated as a consequence of the neutron irradiation setup have not been identified in other publications. As a result, it is not possible to comment on whether radiation hormesis played a role in the large range of reported, but not statistically different, thermal neutron RBE values.

Absorbed dose in the current test system is a result of two neutron capture reactions. The ${ }^{14} \mathrm{~N}(\mathrm{n}, \mathrm{p})^{14} \mathrm{C}$ reaction, accounts for approximately $71 \%$ of the total absorbed dose to blood in rotating quartz tubes. Tertiary electrons from the ${ }^{1} \mathrm{H}(\mathrm{n}, \gamma)^{2} \mathrm{H}$ capture reaction deliver the remaining absorbed dose $(29 \%)$ [12]. When only the ${ }^{14} \mathrm{~N}(\mathrm{n}, \mathrm{p})^{14} \mathrm{C}$ reaction was considered, an elevated DCA RBE $\mathrm{R}_{\mathrm{M}}$ value of $15.5 \pm 2.2$ was revealed (Table 1). This value approaches the theoretical quality factor of 19.17 calculated by Schuhmacher and Siebert [11] for the thermal neutron ${ }^{14} \mathrm{~N}(n, p){ }^{14} \mathrm{C}$ capture reaction. This $\mathrm{RBE}_{\mathrm{M}}$ value of $15.5 \pm 2.2$ is also similar to the quality factor of $18.4 \pm 0.8$ simulated by Ali et al. [12] for the current experimental setup. Furthermore, all $\mathrm{RBE}_{\mathrm{M}}$ values presented here support the bimodal quality factor distribution put forward by Cross and Ing [13] and Stinchcomb and Borak [14] that describes one peak in quality factor within, or nearing, the thermal range and a second peak in the fast-neutron energy range (Figure 1). Cross and Ing's quality factor results were obtained by first-principles calculations for tissue [13], whereas the data trend of Stinchcomb and Borak was acquired using microdosimetry [14].

It is acknowledged that RBE is expected to fall in value for targets deeper into the body. Ali et al. [12] calculated $23 \%$ and $19 \%$ of the total absorbed dose for ${ }^{14} \mathrm{~N}(\mathrm{n}, \mathrm{p}){ }^{14} \mathrm{C}$ reactions 
in the International Commission on Radiation Units and Measurements sphere at the eye lens' depth of $3 \mathrm{~mm}$ and deep organs' depth of $10 \mathrm{~mm}$, respectively, Notwithstanding, the thermal neutron experimental RBE data presented here support bimodal peaks for RBE versus neutron energy, which complements the theoretical quality factor data. This finding may have a significant influence on radiation protection guidelines because the bimodal peaks in quality factor nearly overlay the fluence peaks measured in CANDU reactor workplaces [4], in radiotherapy treatment bunkers [1], and at high altitudes [7], as presented in Figure 4, indicating a high potential for DNA damage for the neutrons encountered in these environments. Consequently, knowledge and understanding of this bimodal trend of the neutron quality factor and, subsequently, of the RBE means that radiation protection aspects that specifically acknowledge a thermal neutron peak warrant further consideration.

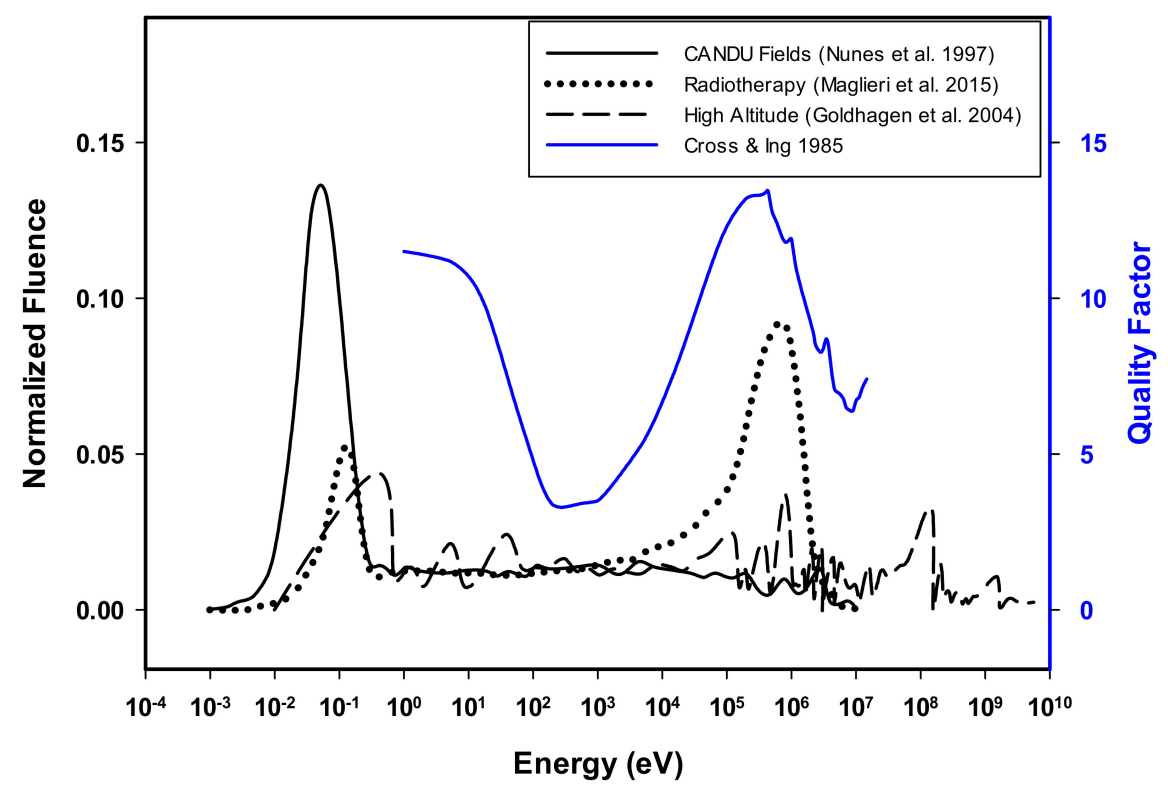

Figure 4. Illustration showing comparison between the smoothed normalized fluence peaks present in radiotherapy treatment facilities [1], CANDU reactor environments [4], and at high altitudes [7] (originally normalized and presented by Ali et al. [12]) and the bimodal quality factor distribution presented by Cross and Ing [13].

\subsection{RBE Accuracy}

There was a gamma dose rate discrepancy between the $64 \mathrm{meV}$ thermal neutrons exposures and the gamma reference radiation for each endpoint. All thermal neutron exposures had an average dose rate of $22 \mathrm{mGy} \mathrm{h}^{-1}$. In contrast, the DCA ${ }^{137} \mathrm{Cs}$ reference radiation exposures were performed using a dose rate of $49.8 \mathrm{~Gy} \mathrm{~h}^{-1}$ [21], and the CBMN reference radiation exposures were performed using two ${ }^{60} \mathrm{Co}$ irradiators with dose rates of 11.2 $\mathrm{Gy} \mathrm{h}^{-1}$ (for doses up $0.5 \mathrm{~Gy}$ ) and $529.8 \mathrm{~Gy} \mathrm{~h}^{-1}$ (for doses between $1 \mathrm{~Gy}$ and $4 \mathrm{~Gy}$ ). It is well-established that low-LET radiations are susceptible to dose rate effects [20], and as such it was not practicable to match the gamma dose rate with the very low thermal neutron dose rate of $22 \mathrm{mGy} \mathrm{h}^{-1}$. However, high-LET radiation, such as the thermal neutron exposures documented here, are not vulnerable to the same dose rate effects because the two lesions required for a dicentric or ring chromosome can be produced by a single track of radiation [20]. This has been previously demonstrated experimentally in human lymphocytes [36]. Other notable neutron RBE studies have accepted a mismatch between the neutron and photon dose rates [37-39]. Given this information, RBE calculations presented here, which use a thermal neutron dose rate of $22 \mathrm{mGy} \mathrm{h}^{-1}$ and a much higher photon dose rate, were deemed acceptable. 
Publications regarding neutron RBE in lymphocytes are often related to biological dosimetry capability. To allow for comparison, whole blood irradiation and consequent lymphocyte phytohemagglutinin stimulation were chosen to allow for direct comparison to previous work. However, lymphocytes are known to be a more radiosensitive cell type [40], and care should be taken before extrapolating these results to other cell types.

This is the second peer-reviewed publication from our laboratory that evaluates the $\mathrm{RBE}$ of neutrons. An earlier study of ${ }^{252} \mathrm{Cf}$ fast neutrons of $2.1 \mathrm{MeV}$ (average energy) described DCA RBE $\mathrm{R}_{\mathrm{M}}$ values of $15.0 \pm 2.2$ and $25.7 \pm 3.8$ for the neutron-plus-gamma and neutron-only dose components, respectively [29]. Our thermal neutron DCA RBE $\mathrm{M}_{\mathrm{M}}$ values of $11.3 \pm 1.6$ (for both ${ }^{14} \mathrm{~N}(\mathrm{n}, \mathrm{p}){ }^{14} \mathrm{C}$ and ${ }^{1} \mathrm{H}(\mathrm{n}, \gamma)^{2} \mathrm{H}$ reactions) and $15.5 \pm 2.2$ (for ${ }^{14} \mathrm{~N}(\mathrm{n}, \mathrm{p}){ }^{14} \mathrm{C}$ reaction alone) are slightly lower than the ${ }^{252} \mathrm{Cf}$ values, a finding that is consistent with those of other studies. Specifically, DCA RBE $\mathrm{M}$ in human peripheral blood lymphocytes has been found to increase from slow-neutron energies ( $\mathrm{a}$ few hundred $\mathrm{eV}$ ) up to approximately $0.385 \mathrm{MeV}\left(\mathrm{RBE}_{\mathrm{M}}=94.4 \pm 38.9\right)$ [41]. Beyond this point, the DCA RBE $\mathrm{M}$ begins to decrease with increasing neutron energy, but does not reach unity. This trend corresponds with the currently ICRP recommended monomodal peak for quality factor that is approximately 20 nearing $1 \mathrm{MeV}[10]$.

\subsection{Limitations}

The scoring of both the DCA and CBMN assay was done manually. To achieve high accuracy and precision, scoring was performed by a qualified individual within the Canadian biodosimetry network who undergoes annual network intercomparisons to ensure effective analysis methods [42]. To avoid scoring bias, samples were blinded prior to microscopy.

To generate dose response curves, data was pooled from three donors. Except for the 12.0 mGy dose point, 500 or more cells per donor per dose point were compiled for the DCA. At low cell numbers, it is possible that inter-individual differences in spontaneous dicentric frequency may have been missed.

For the RBE calculation at the low doses examined here, it was necessary to extrapolate the gamma dose response from the DCA and CBMN lines of best fit, rather than from matched data points. This is an unavoidable consequence of this low-dose work, and highlights the importance of research into novel biodosimetry assays that can quantify low-dose exposures.

It can be difficult to extrapolate RBE from in vitro blood exposures to whole-body exposure situations. The dose contribution of the ${ }^{1} \mathrm{H}(\mathrm{n}, \gamma)^{2} \mathrm{H}$ reaction is much lower in a test tube than for a whole body dose [10]. As mentioned in the section above on Bimodal Neutron RBE Values, the RBE values can be expected to be reduced for thermal neutron exposure of shallow targets such as the eyes and skin. Nevertheless, these results demonstrate that thermal neutrons can cause complex clustered damage in tissue and should not be dismissed as being less hazardous than higher energy neutrons.

\section{Materials and Methods}

\subsection{Blood Donors}

Blood samples were drawn by venipuncture from healthy blood donors at CNL (Chalk River, ON, Canada) into evacuated tubes containing sodium citrate anticoagulant (BD, Franklin Lakes, NJ, USA). All blood donors were volunteers who willingly agreed to participate in a research proposal for which the ethics had been approved by Veritas Independent Review Board (Montreal, QC, Canada). Donors were non-smokers who reported feeling healthy on the day of the blood draw and had no history of radiotherapy or chemotherapy treatment. Three donors, two males and one female, participated in the DCA and CBMN studies. Enrollment of three or fewer donors is common in neutron RBE studies $[18,29,41,43,44]$. Donors were between 20 and 50 years old. Following venipuncture, anticoagulated whole blood was immediately transferred into quartz test tubes and then transported to the irradiation facility. 


\subsection{Irradiation Conditions}

The $64 \mathrm{meV}$ thermal neutron irradiations were completed at CNL in the NRU reactor using the E3 spectrometer of the Canadian Neutron Beam Centre. The details of the beamline configuration and the associated physical modelling of the test system were described previously by Ali et al. [12]. Briefly, a pyrolytic graphite (PG) crystal in the E3 spectrometer selected for an average neutron kinetic energy of $64 \mathrm{meV}$. The ${ }^{14} \mathrm{~N}$ mass fraction in blood was modelled at $2.96 \%$. The total absorbed dose per unit neutron fluence delivered to a blood sample was calculated to be $0.274 \mathrm{pGy} \mathrm{cm}^{2} \mathrm{n}^{-1}$ [12]. The ${ }^{14} \mathrm{~N}(\mathrm{n}, \mathrm{p}){ }^{14} \mathrm{C}$ capture reaction accounted for nearly $71 \%$ of the total absorbed dose, and tertiary electrons from the ${ }^{1} \mathrm{H}(\mathrm{n}, \gamma){ }^{2} \mathrm{H}$ capture reaction were responsible for the remaining absorbed dose. Quartz test tubes, each containing $4.2 \mathrm{~mL}$ of whole blood, were positioned on a computer-controlled gantry in front of the beam port. The tubes were rotated at $60 \mathrm{rpm}$ during the irradiation period to ensure a uniform sample exposure [12] and were maintained at room temperature throughout the irradiation and transportation periods to minimize the effects of concurrent DNA repair [20]. The average neutron fluence rate was quantified using gold foil activation analysis. Due to frequent changes in the reactor power, the neutron fluence rate also varied with time. The average neutron fluence rate throughout the irradiation campaign was $2.25 \times 10^{7} \pm 0.03 \times 10^{7} \mathrm{n} \mathrm{cm}^{-2} \mathrm{~s}^{-1}$ and the average absorbed dose rate delivered to the blood samples was $22 \pm 0.9 \mathrm{mGy} \mathrm{h}^{-1}$. Cell cultures were established $18 \mathrm{~h}$ after exposure. This time interval ensured sufficient radionuclide decay for safe sample handling.

\subsection{Assays}

\subsubsection{Dicentric Chromosome Assay}

Whole blood from three donors was irradiated with neutron doses of $6.0 \mathrm{mGy}$ to 82.1 mGy. Duplicate cultures were established in Nunc T-25 flasks (Thermo Fisher Scientific Inc., Waltham, MA, USA). Samples were harvested for slide making and fluorescenceplus-Giemsa staining following a $48 \mathrm{~h}$ incubation according to the IAEA recommendations for biological dosimetry laboratories [20], as described previously by Paterson et al. [29]. Slides were blinded and metaphase spreads were imaged at $630 \times$ magnification using the Metafer slide scanning platform (Metasystems Group Inc., Newton, MA, USA). Complete metaphase spreads in first division were scored manually according to criteria described previously [29]. A minimum of 500 cells per donor per dose point were scored for all dose points, except for $12.0 \mathrm{mGy}$ where only 1414 cells for the three donors combined were available (Table 2).

\subsubsection{Cytokinesis-Block Micronucleus Assay}

Whole blood from three donors was exposed to $64 \mathrm{meV}$ thermal neutrons. Doses ranged from $21.7 \mathrm{mGy}$ to $85.0 \mathrm{mGy}$. Whole blood cultures were established according to a modified procedure of Fenech et al. [27], previously described by McNamee et al. [30]. Cultures were incubated for $72 \mathrm{~h}$, with cytochalasin B (Millipore Sigma, Burlington, MA, USA) present for the final $28 \mathrm{~h}$. Slides were blinded and stained with acridine orange to allow for fluorescence microscopy. Binucleated cells were manually scored at $400 \times$ magnification according to criteria provide by Fenech et al. [27]. A total of 5000 cells were scored per donor per dose point (Table 4).

\subsection{Statistics}

Statistical analysis for the DCA and CBMN assay was completed according to the IAEA cytogenetic dosimetry recommendations [20]. The results were tested for compliance with the Poisson distribution by calculating the dispersion index (variance, $\sigma^{2} /$ mean, $y$ ) and the $u$-test statistic. A dispersion index of unity confirms agreement with the Poisson distribution. Dispersion indices differing from unity were further tested using the $u$ test, where statistic values above 1.96 indicated non-Poisson over-dispersion at the $5 \%$ significance level [20,45]. 
The Dose Estimate software package (version 5.2) was used to ensure proper DCA and $C B M N$ data curve-fitting [46]. Linear-quadratic regression is presented in the form $A=c+\alpha D+\beta D^{2}$, where $A$ is the frequency of aberrations at a given dose point, $c$ is the background frequency of aberrations, $\alpha$ is the linear dose response coefficient (aberrations produced by a single track of radiation), $\beta$ is the quadratic dose response coefficient (aberrations produced by two tracks of radiation), and $D$ represents the dose in Gy. Errors were reported as either standard deviation (SD) or standard error (SE). The chi-squared test $\left(\chi^{2}\right)$ was used to evaluate the fit of the dose response curves, and the significance of the dose response equation coefficients was evaluated using the $z$-test. The $p$-values less than 0.05 were considered statistically significant.

\subsection{Dose and RBE Calculations}

The number of dicentric and ring chromosome aberrations attributable only to the $(n, p)$ reaction were calculated using the method described by Schmid et al. [18]. Briefly, the dose contribution from the ${ }^{1} \mathrm{H}(\mathrm{n}, \gamma)^{2} \mathrm{H}$ capture reaction was calculated using the data for absorbed dose per unit neutron fluence previously derived by Ali et al. [12]. This information was used to calculate the number of photon-induced aberrations per cell at each dose point based on the previously published in-house ${ }^{137} \mathrm{C}$ s dose response curve [21]. The number of photon-induced aberrations per cell was then subtracted from the total number of aberrations per cell to give a value for the (n,p)-induced aberrations per cell. This method could not be applied to the CBMN assay data due to the differing background aberration rate between the $64 \mathrm{meV}$ neutron samples and the reference ${ }^{60} \mathrm{Co}$ dose response curve.

The RBE for $64 \mathrm{meV}$ neutrons was calculated using two methods: the maximum $\mathrm{RBE}_{\mathrm{M}}$ method, and the dose-specific RBE method. The $\mathrm{RBE}_{\mathrm{M}}$ was calculated as the ratio of the regression equation $\alpha$-coefficient values from the thermal neutron exposures to those of the photon dose response curves [20]. Dose-specific RBE values were calculated as the ratio of gamma dose to neutron dose required to produce the same effect.

\section{Conclusions}

A linear dose response relationship for thermal neutrons was found for DCA and CBMN assays following low doses from $64 \mathrm{meV}$ thermal neutrons. High $\mathrm{RBE}_{\mathrm{M}}$ values of $11.3 \pm 1.6$ and $15.5 \pm 2.2$ were found for the DCA, when all neutron capture reactions were considered and when only the ${ }^{14} \mathrm{~N}(\mathrm{n}, \mathrm{p}){ }^{14} \mathrm{C}$ reaction was considered, respectively. As expected, $\mathrm{RBE}_{\mathrm{M}}$ of $9.0 \pm 1.1$ for the $\mathrm{CBMN}$ assay was similar to the $\mathrm{DCA} \mathrm{RBE}_{\mathrm{M}}$ when all neutron capture reactions were considered. These consistent, high-accuracy RBE values are about four times higher than the current ICRP $w_{\mathrm{R}}$ value of 2.5 for thermal neutron exposures, but similar to the theoretical quality factors described for the thermal neutron ${ }^{14} \mathrm{~N}(\mathrm{n}, \mathrm{p}){ }^{14} \mathrm{C}$ capture reaction $[11,12]$. Our experimental $\mathrm{RBE}_{\mathrm{M}}$ values lend support to a theoretically derived bimodal quality factor trend that describes not only a fast-neutron peak but also a second peak for elevated quality factor values in the low-energy range. This work accurately confirms that the low-energy thermal neutrons found in radiotherapy treatment bunkers, in CANDU reactor facilities, and during spaceflight can cause significant DNA damage in healthy tissues, which could theoretically result in genomic instability and mutation-induced carcinogenesis, cataracts, and other health effects. Future work should examine whether this phenomenon persists in cell types of differing radiosensitivity or in animal models. If substantiated, this bimodal trend in neutron quality factor justifies consideration in radiation protection recommendations.

Author Contributions: Conceptualization, R.B.R. and L.C.P.; methodology, L.C.P., A.F. and M.S.; formal analysis, L.C.P.; investigation, L.C.P., A.F., M.S., C.C., C.B., R.R. and R.B.R.; writing-original draft preparation, L.C.P.; writing-review and editing, R.B.R., F.A. and M.S.; visualization, L.C.P., F.A. and R.B.R.; supervision, R.B.R., J.K. and N.Y.; project administration, R.B.R.; funding acquisition, R.B.R. All authors have read and agreed to the published version of the manuscript. 
Funding: This work was funded by Atomic Energy of Canada Limited's Federal Nuclear Science \& Technology Work Plan.

Institutional Review Board Statement: The study was approved by Veritas Independent Review Board (Montreal, QC, Canada).

Informed Consent Statement: Informed consent was obtained from all subjects involved in the study.

Acknowledgments: The authors would like to acknowledge Rosetta McGirl and Karen Barry for performing routine phlebotomy in support of this research project, Brianna Beebe for radiation protection advice, Justin Wegner for radiation protection surveying, Dennis Deng for assistance with statistics, Daniel Hunton for reviewing the manuscript, and Helena Rummens for copyediting.

Conflicts of Interest: The authors declare no conflict of interest.

\section{References}

1. Maglieri, R.; Licea, A.; Evans, M.D.C.; Seuntjens, J.; Kildea, J. Measuring neutron spectra in radiotherapy using the nested neutron spectrometer. Med. Phys. 2015, 42, 6162-6169. [CrossRef] [PubMed]

2. Newhauser, W.D.; Durante, M. Assessing the risk of second malignancies after modern radiotherapy. Nat. Cancer 2011, 11, 438-448. [CrossRef] [PubMed]

3. Kildea, J. The Canadian Neutron-Induced Carcinogenic Effects Research Program-A research program to investigate neutron relative biological effectiveness for carcinogenesis with a particular focus on secondary (by-product) neutrons in high-energy radiation therapy. Radiat. Environ. Med. 2017, 6, 55-61.

4. Nunes, J.; Cross, W.; Waker, A. Feasibility of creating "CANDU-like" workplace neutron fields in an existing irradiation facility. Radiat. Prot. Dosim. 1997, 72, 11-20. [CrossRef]

5. El-Jaby, S.; Lewis, B.J.; Tomi, L. On the decision making criteria for cis-lunar reference mission scenarios. Life Sci. Space Res. 2019, 21, 25-39. [CrossRef]

6. El-Jaby, S.; Richardson, R.B. Monte Carlo simulations of the secondary neutron ambient and effective dose equivalent rates from surface to suborbital altitudes and low Earth orbit. Life Sci. Space Res. 2015, 6, 1-9. [CrossRef]

7. Goldhagen, P.; Clem, J.M.; Wilson, J.W. The energy spectrum of cosmic-ray induced neutrons measured on an airplane over a wide range of altitude and latitude. Radiat. Prot. Dosim. 2004, 110, 387-392. [CrossRef]

8. Zhang, S.; Wimmer-Schweingruber, R.F.; Yu, J.; Wang, C.; Fu, Q.; Zou, Y.; Sun, Y.; Wang, C.; Hou, D.; Böttcher, S.I.; et al. First measurements of the radiation dose on the lunar surface. Sci. Adv. 2020, 6, eaaz1334. [CrossRef]

9. IAEA. Current Status of Neutron Capture Therapy; IAEA: Vienna, Austria, 2001.

10. ICRP. Relative biological effectiveness (RBE), quality factor $(\mathrm{Q})$, and radiation weighting factor (wR): ICRP publication 92. Ann. ICRP 2003, 33, 1-121.

11. Schuhmacher, H.; Seibert, B. Quality factors and ambient dose equivalent for neutrons based on the new ICRP recommendations. Radiat. Prot. Dosim. 1992, 40, 85-98. [CrossRef]

12. Ali, F.; Atanackovic, J.; Boyer, C.; Festarini, A.; Kildea, J.; Paterson, L.; Rogge, R.; Stuart, M.; Richardson, R.B. Dosimetric and microdosimetric analyses for blood exposed to reactor-derived thermal neutrons. J. Radiol. Prot. 2018, 38, 1037-1052. [CrossRef]

13. Cross, W.; Ing, H. Conversion and quality factors relating neutron fluence and dosimetric quantities. Radiat. Prot. Dosim. 1985, 10, 29-42. [CrossRef]

14. Stinchcomb, T.G.; Borak, T.B. Neutron quality parameters versus energy below $4 \mathrm{MeV}$ from microdosimetric calculations. Radiat. Res. 1983, 93, 1-18. [CrossRef]

15. Stricklin, D.L.; VanHorne-Sealy, J.; Rios, C.I.; Carnell, L.A.S.; Taliaferro, L.P. Neutron radiobiology and dosimetry. Radiat. Res. 2021, 195, 480-496. [CrossRef] [PubMed]

16. Sevan'kaev, A.V.; Zherbin, E.A.; Luchnik, N.V.; Obaturov, G.M.; Kozlov, V.M. Cytogenetic effects induced by neutrons in human peripheral blood lymphocytes in vitro. I. Dose-effect relationship for different types of chromosome aberrations when exposed to neutrons with different energies. Генетика 1979, 15, 1046-1060.

17. Wojcik, A.; Obe, G.; Lisowska, H.; Czub, J.; Nievaart, V.; Moss, R.; Huiskamp, R.; Sauerwein, W. Chromosomal aberrations in peripheral blood lymphocytes exposed to a mixed beam of low energy neutrons and gamma radiation. J. Radiol. Prot. 2012, 32, 261-274. [CrossRef]

18. Schmid, E.; Wagner, F.M.; Canella, L.; Romm, H.; Schmid, T.E. RBE of thermal neutrons for induction of chromosome aberrations in human lymphocytes. Radiat. Environ. Biophys. 2012, 52, 113-121. [CrossRef] [PubMed]

19. Sasaki, M.S.; Endo, S.; Ejima, Y.; Saito, I.; Okamura, K.; Oka, Y.; Hoshi, M. Effective dose of A-bomb radiation in Hiroshima and Nagasaki as assessed by chromosomal effectiveness of spectrum energy photons and neutrons. Radiat. Environ. Biophys. 2006, 45, 79-91. [CrossRef] [PubMed]

20. IAEA. Cytogenetic Dosimetry: Applications in Preparedness for and Response to Radiation Emergencies; IAEA: Vienna, Austria, 2011.

21. Flegal, F.N.; DeVantier, Y.; Marro, L.; Wilkins, R. Validation of QuickScan dicentric chromosome analysis for high throughput radiation biological dosimetry. Health Phys. 2012, 102, 143-153. [CrossRef] 
22. Lloyd, D.C.; Edwards, A.A. Chromosome aberrations in human lymphocytes: Effect of radiation quality, dose, and dose rate. In Radiation-Induced Chromosome Damage in Man; Ishihara, T., Sasaki, M.S., Eds.; AR Liss: New York, NY, USA, 1983.

23. Bauchinger, M.; Schmid, E.; Streng, S.; Dresp, J. Quantitative analysis of the chromosome damage at first division of human lymphocytes after ${ }^{60}$ Co gamma-irradiation. Radiat. Environ. Biophys. 1983, 22, 225-230. [CrossRef]

24. Sasaki, M.; Kobayashi, K.; Hieda, K.; Yamada, T.; Ejima, Y.; Maezawa, H.; Furusawa, Y.; Ito, T.; Okada, S. Induction of chromosome aberrations in human lymphocytes by monochromatic X-rays of quantum energy between $4 \cdot 8$ and 14.6 keV. Int. J. Radiat. Biol. 1989, 56, 975-988. [CrossRef]

25. Montgomery, L.; Lund, C.M.; Landry, A.; Kildea, J. Towards the characterization of neutron carcinogenesis through direct action simulations of clustered DNA damage. Phys. Med. Biol. 2021, 66, 205011. [CrossRef] [PubMed]

26. Okumura, K.; Kinashi, Y.; Kubota, Y.; Kitajima, E.; Okayasu, R.; Ono, K.; Takahashi, S. Relative biological effects of neutron mixedbeam irradiation for boron neutron capture therapy on cell survival and DNA double-strand breaks in cultured mammalian cells. J. Radiat. Res. 2012, 54, 70-75. [CrossRef] [PubMed]

27. Fenech, M.; Chang, W.; Kirsch-Volders, M.; Holland, N.; Bonassi, S.; Zeiger, E. HUMN project: Detailed description of the scoring criteria for the cytokinesis-block micronucleus assay using isolated human lymphocyte cultures. Mutat. Res. Toxicol. Environ. Mutagen. 2003, 534, 65-75. [CrossRef]

28. Fenech, M. The cytokinesis-block micronucleus technique: A detailed description of the method and its application to genotoxicity studies in human populations. Mutat. Res. Mol. Mech. Mutagen. 1993, 285, 35-44. [CrossRef]

29. Paterson, L.C.; Yonkeu, A.; Ali, F.; Priest, N.D.; Boreham, D.R.; Seymour, C.B.; Norton, F.; Richardson, R.B. Relative biological effectiveness and non-Poissonian distribution of dicentric chromosome aberrations following californium-252 neutron exposures of human peripheral blood lymphocytess. Radiat. Res. 2020, 195, 211-217. [CrossRef] [PubMed]

30. McNamee, J.P.; Flegal, F.N.; Greene, H.B.; Marro, L.; Wilkins, R. Validation of the cytokinesis-block micronucleus (CBMN) assay for use as a triage biological dosimetry tool. Radiat. Prot. Dosim. 2009, 135, 232-242. [CrossRef] [PubMed]

31. Romm, H.; Wilkins, R.C.; Coleman, C.N.; Lillis-Hearne, P.K.; Pellmar, T.C.; Livingston, G.K.; Awa, A.A.; Jenkins, M.S.; Yoshida, M.A.; Oestreicher, U.; et al. Biological dosimetry by the triage dicentric chromosome assay: Potential implications for treatment. Radiat. Res. 2011, 175, 397-404. [CrossRef] [PubMed]

32. Vral, A.; Verhaegen, F.; Thierens, H.; De Ridder, L. Micronuclei induced by fast neutrons versus ${ }^{60}$ Co gamma-rays in human peripheral blood lymphocytes. Int. J. Radiat. Biol. 1994, 65, 321-328. [CrossRef] [PubMed]

33. Lehman, R.R.; Archer, K.J. Penalized negative binomial models for modeling an overdispersed count outcome with a highdimensional predictor space: Application predicting micronuclei frequency. PLoS ONE 2019, 14, e0209923. [CrossRef]

34. Gajendiran, N.; Tanaka, K.; Kumaravel, T.S.; Kamada, N. Neutron-induced adaptive response studied in go human lymphocytes using the comet assay. J. Radiat. Res. 2001, 42, 91-101. [CrossRef] [PubMed]

35. Rithidech, K.N.; Scott, B.R. Evidence for radiation hormesis after in vitro exposure of human lymphocytes to low doses of ionizing radiation. Dose-Response 2008, 6, 252-271. [CrossRef] [PubMed]

36. Tanaka, K.; Gajendiran, N.; Kamada, N. Relative biological effectiveness (RBE) and dose rate dependent ratio of translocation to dicentric chromosome yield in ${ }^{252}$ Cf neutrons. Indian J. Sci. Technol. 2009, 2, 1-11. [CrossRef]

37. Schmid, E.; Regulla, D.; Guldbakke, S.; Schlegel, D.; Bauchinger, M. The effectiveness of monoenergetic neutrons at 565 keV in producing dicentric chromosomes in human lymphocytes at low doses. Radiat. Res. 2000, 154, 307-312. [CrossRef]

38. Schmid, E.; Regulla, D.; Guldbakke, S.; Schlegel, D.; Roos, M. Relative biological effectiveness of 144 keV neutrons in producing dicentric chromosomes in human lymphocytes compared with ${ }^{60} \mathrm{Co}$ gamma rays under head-to-head conditions. Radiat. Res. 2002, 157, 453-460. [CrossRef]

39. Vral, A.; Cornelissen, M.; Thierens, H.; Louagie, H.; Philippe, J.; Strijckmans, K.; De Ridder, L. Apoptosis induced by fast neutrons versus ${ }^{60}$ Co gamma-rays in human peripheral blood lymphocytes. Int. J. Radiat. Biol. 1998, 73, 289-295. [PubMed]

40. Deschavanne, P.J.; Fertil, B. A review of human cell radiosensitivity in vitro. Int. J. Radiat. Oncol. 1996, 34, 251-266. [CrossRef]

41. Schmid, E.; Schlegel, D.; Guldbakke, S.; Kapsch, R.-P.; Regulla, D. RBE of nearly monoenergetic neutrons at energies of 36 keV-14.6 MeV for induction of dicentrics in human lymphocytes. Radiat. Environ. Biophys. 2003, 42, 87-94. [CrossRef] [PubMed]

42. Wilkins, R.C.; Beaton-Green, L.A.; Lachapelle, S.; Kutzner, B.C.; Ferrarotto, C.; Chauhan, V.; Marro, L.; Livingston, G.K.; Greene, H.B.; Flegal, F.N. Evaluation of the annual Canadian biodosimetry network intercomparisons. Int. J. Radiat. Biol. 2015, 91, 443-451. [CrossRef]

43. Lloyd, D.; Purrott, R.; Reeder, E.; Edwards, A.; Dolphin, G. Chromosome aberrations induced in human lymphocytes by radiation from ${ }^{252}$ Cf. Int. J. Radiat. Biol. Relat. Stud. Phys. Chem. Med. 1978, 34, 177-186. [CrossRef] [PubMed]

44. Lloyd, D.C.; Edwards, A.A.; Prosser, J.S.; Bolton, D.; Sherwin, A.G. Chromosome aberrations induced in human lymphocytes by D-T neutrons. Radiat. Res. 1984, 98, 561-573. [CrossRef] [PubMed]

45. Szluinska, M.; Edwards, A.A.; Lloyd, D.C. Statistical Methods for Biological Dosimetry; HPA Radiation Protection Division: Chilton, WI, USA, 2005.

46. Ainsbury, E.A.; Lloyd, D.C. Dose estimation software for radiation biodosimetry. Health Phys. 2010, 98, 290-295. [CrossRef] [PubMed] 